\title{
Hybrid Multilevel Inverter with Single DC Source
}

\author{
Haiwen Liu ${ }^{1}$, Leon M. Tolbert ${ }^{1,2}$, Burak Ozpineci ${ }^{2}$, Zhong Du ${ }^{3}$ \\ 1. The University of Tennessee \\ Knoxville, TN 37996 \\ 2. Oak Ridge National Laboratory \\ 3. Parker-Hannifin Corp. \\ Knoxville, TN 37932 \\ Olive Branch, MI 38654
}

\begin{abstract}
A hybrid multilevel inverter model based on the PSIM and MATLAB/SIMULINK is presented in this paper. It consists of a standard 3-leg inverter (one leg for each phase) and $\mathrm{H}$-bridge in series with each inverter leg. The inverter can be used in hybrid electric vehicles (HEV) and electric vehicles (EV). The co-simulation model is employed in order to take full advantage of different power electronics simulation software. Specifically, the main circuit model is developed using PSIM, and the control model is developed using MATLAB/SIMULINK. An experimental 5-level hybrid inverter is tested, which is controlled by multilevel carrier-based PWM signals. The simulation yields a good estimation for the test results of the inverter.
\end{abstract}

\section{INTRODUCTION}

The multilevel inverter has gained much attention in recent years due to its advantages in high power possibility with low switching frequency and low harmonics. The general function of the multilevel inverter is to synthesize a desired high voltage from several levels of dc voltages [1][2][3]. The dc sources can be batteries, fuel cells, etc., where all the dc levels are considered to be identical.

In this paper, the proposed hybrid multilevel inverter includes a standard 3-leg inverter (one leg for reach phase) and $\mathrm{H}$-bridge in series with each inverter leg. The inverter can be used in hybrid electric vehicles (HEV) and electric vehicles (EV). Also, it is possible to increase the power density because the inverter removes the bulky inductor of the present DC-DC boost converter. To develop the model of hybrid multilevel inverter, a simulation is done based on the PSIM and MATLAB/SIMULINK platforms. The cosimulation technology has become increasingly popular because it can make full use of the advantages of different power electronics simulation software packages. PSIM is a kind of simulation software specifically designed for power electronics and motor drives [4]. It can simulate the power electronics circuit, but is not very convenient to realize many control functions. SIMULINK is powerful in building the control models. Their integration makes the design and analysis of hybrid multilevel inverter more detailed and complete.

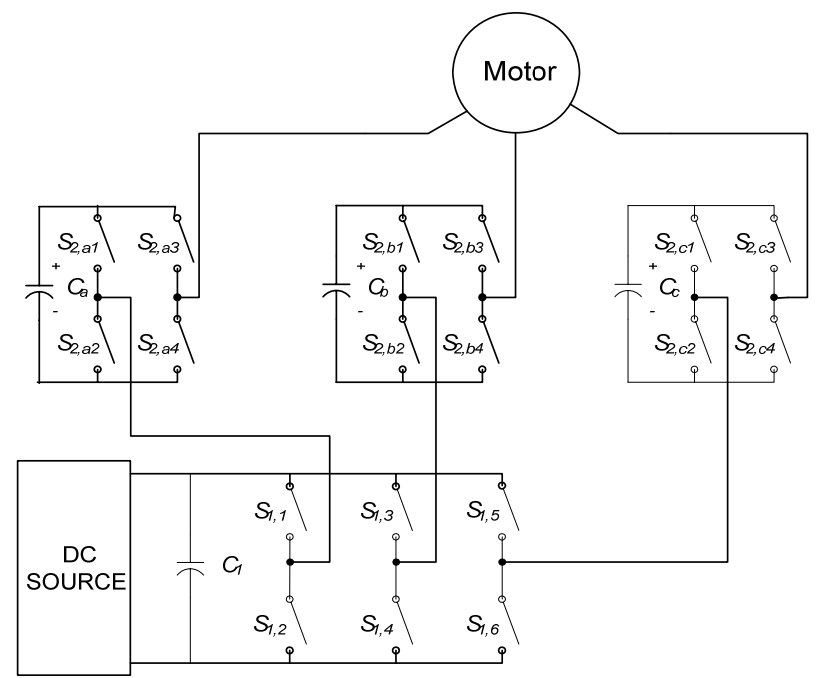

Fig. 1. Topology of the hybrid multilevel inverter.

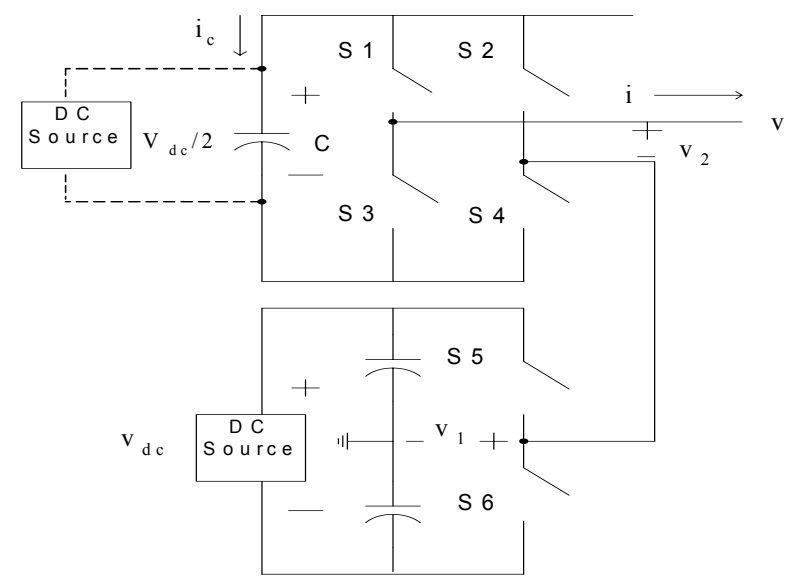

Fig. 2. Simplified single-phase topology of the hybrid multilevel inverter.

\section{OPERATION PRINCIPLE OF THE HybRID MUlTILEVEL INVERTER}

Fig. 1 shows the topology of the proposed hybrid shows the topology of the proposed hybrid multilevel inverter. A simplified single-phase topology is shown in Fig. 2. The bottom is one leg of a standard 3-leg inverter with a dc power 


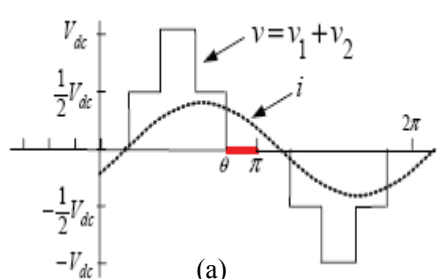

(a)
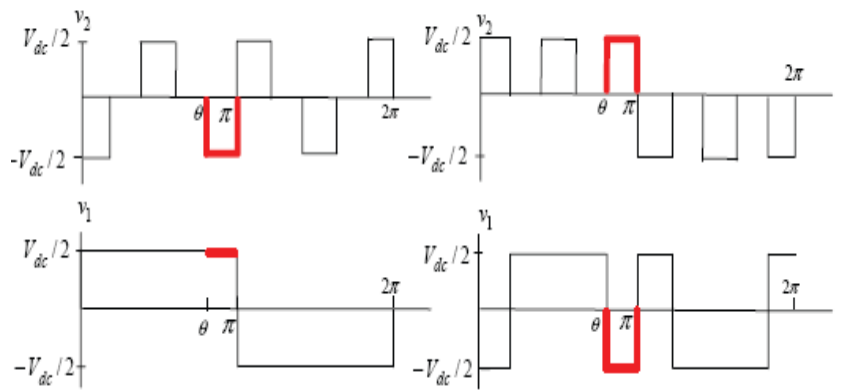

(b)

(c)

Fig. 3. Capacitor voltage regulation process.

source. The top is an H-bridge in series with each standard inverter leg. The H-bridge can use a separate dc power source or a capacitor as the dc power source [5][6].

The output voltage $v_{1}$ of this leg (with respect to the ground) is either $+V_{d c} / 2\left(\mathrm{~S}_{5}\right.$ closed $)$ or $-V_{d c} / 2\left(\mathrm{~S}_{6}\right.$ closed $)$. This leg is connected in series with a full $\mathrm{H}$-bridge which in turn is supplied by a capacitor voltage. If the capacitor is kept charged to $V_{d c} / 2$, then the output voltage of the H-bridge can take on the values $+V_{d c} / 2\left(\mathrm{~S}_{1}, \mathrm{~S}_{4}\right.$ closed $), 0\left(\mathrm{~S}_{1}, \mathrm{~S}_{2}\right.$ closed or $\mathrm{S}_{3}, \mathrm{~S}_{4}$ closed), or $-V_{d c} / 2\left(\mathrm{~S}_{2}, \mathrm{~S}_{3}\right.$ closed $)$. An example output waveform that this topology can achieve is shown in the top of Fig. 3 (a). When the output voltage $v=v_{1}+v_{2}$ is required to be zero, one can either set $v_{l}=+V_{d c} / 2$ and $v_{2}=-V_{d c} / 2$ or $v_{1}$ $=-V_{d c} / 2$ and $v_{2}=+V_{d c} / 2$. It is this flexibility in choosing how to make that output voltage zero that is exploited to regulate the capacitor voltage.

When only a dc power source is used in the inverter, that is, the H-bridge uses a capacitor as the dc power source, the capacitor's voltage regulation control details are illustrated in Fig. 3. During $\theta_{1} \leq \theta \leq \pi$, the output voltage in Fig. 3 is zero and the current $i>0$. If $\mathrm{S}_{1}, \mathrm{~S}_{4}$ are closed (so that $v_{2}=+V_{d c} / 2$ ) along with $\mathrm{S}_{6}$ closed (so that $v_{1}=-V_{d c} / 2$ ), then the capacitor is discharging $\left(i_{c}=-i<0\right.$ see Fig. $\left.3(\mathrm{~b})\right)$ and $v=v_{1}+v_{2}=0$. On the other hand, if $\mathrm{S}_{2}, \mathrm{~S}_{3}$ are closed (so that $v_{2}=-V_{d c} / 2$ ) and $\mathrm{S}_{5}$ is also closed (so that $v_{1}=+V_{d c} / 2$ ), then the capacitor is charging $\left(i_{c}=i>0\right.$ see Fig. 3 (c)) and $v=v_{l}+v_{2}=0$. The case $i<0$ is accomplished by simply reversing the switch positions of the $i>0$ case for charge and discharge of the capacitor. Consequently, the method consists of monitoring the output current and the capacitor voltage so that during periods of zero voltage output, either the switches $S_{1}, S_{4}$, and $\mathrm{S}_{6}$ are closed or the switches $\mathrm{S}_{2}, \mathrm{~S}_{3}, \mathrm{~S}_{5}$ are closed depending on whether it is necessary to charge or discharge the capacitor.

As Fig. 3 illustrates, this method of regulating the capacitor voltage depends on the voltage and current not being in phase. That means one needs positive (or negative) current when the voltage is passing through zero in order to charge or discharge the capacitor. Consequently, the amount of capacitor voltage the scheme can regulate depends on the phase angle difference of output voltage and current.

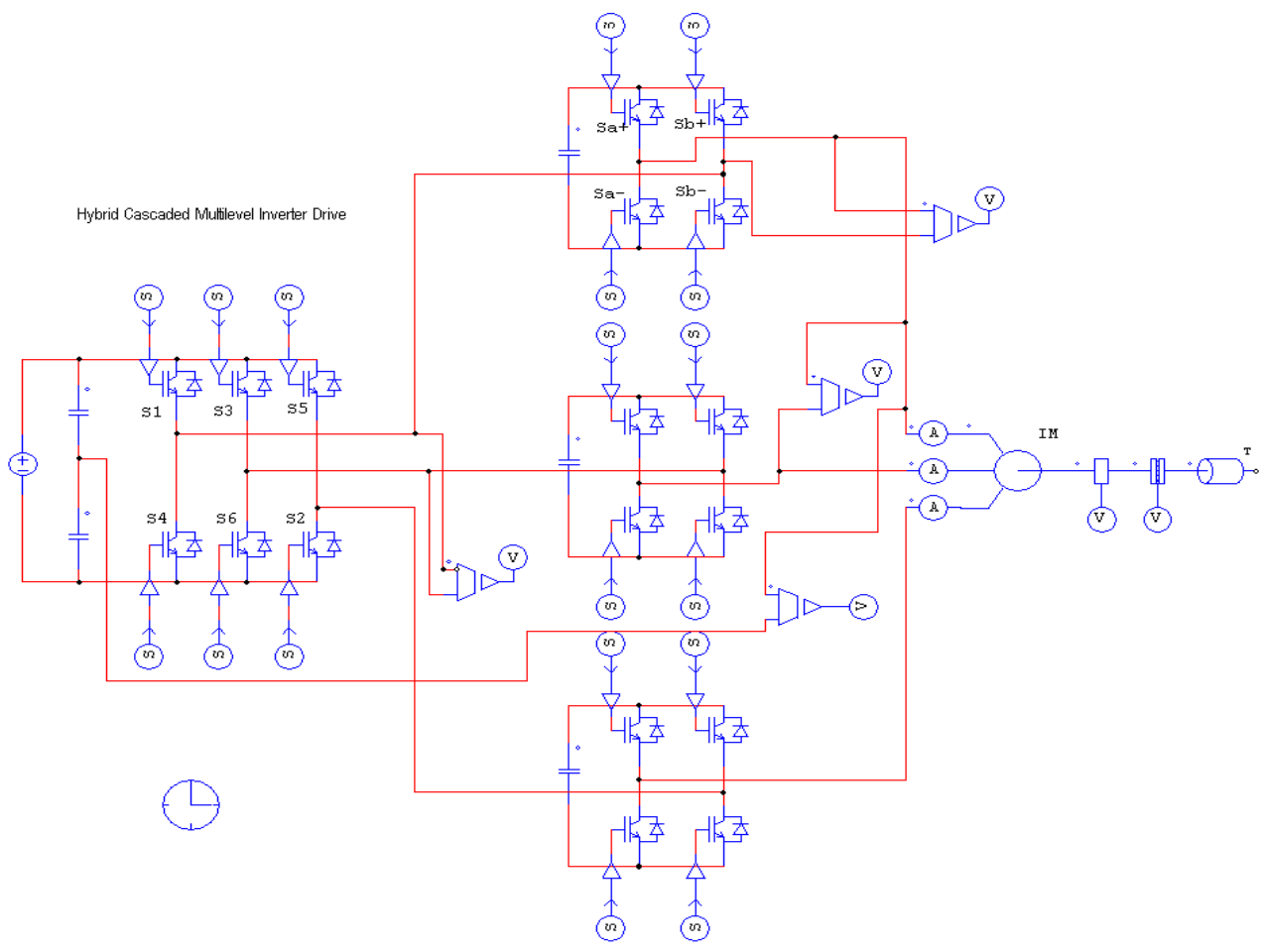

Fig. 4. PSIM model for the hybrid multilevel inverter. 


\section{Psim ANd Simulink Co-Simulation}

The modulation control schemes for multilevel inverter can be divided into two categories, fundamental switching frequency [5] and high switching frequency PWM, and both can be used for the hybrid multilevel inverter. In this paper, the simulation model based on the PSIM and MATALB/SIMULINK is developed under the multilevel carrier-based PWM mode. Multilevel carrier-based PWM trategies are the most popular methods because they are easily implemented. Three major carrier-based techniques that are used in a conventional inverter can be applied in a multilevel inverter: sinusoidal PWM (SPWM), third harmonic injection PWM (THPWM), and space vector PWM (SVM). SPWM is a very popular method in industrial applications. It uses several triangle carrier signals, one carrier for each level and one reference, or modulation, signal per phase. [3][7]. In the proposed inverter, the top H-bridge inverter is operated under the SPWM mode and the bottom standard 3-leg inverter is operated under square-wave mode in order to reduce switching loss.

For an m-level inverter, the amplitude modulation index, $m_{a}$, is defined as

$$
m_{a}=\frac{A_{m}}{(m-1) A_{C}}
$$

Where, $A_{m}$ is the peak-to-peak reference amplitude, $A_{c}$ is the peak-to-peak carrier amplitude.

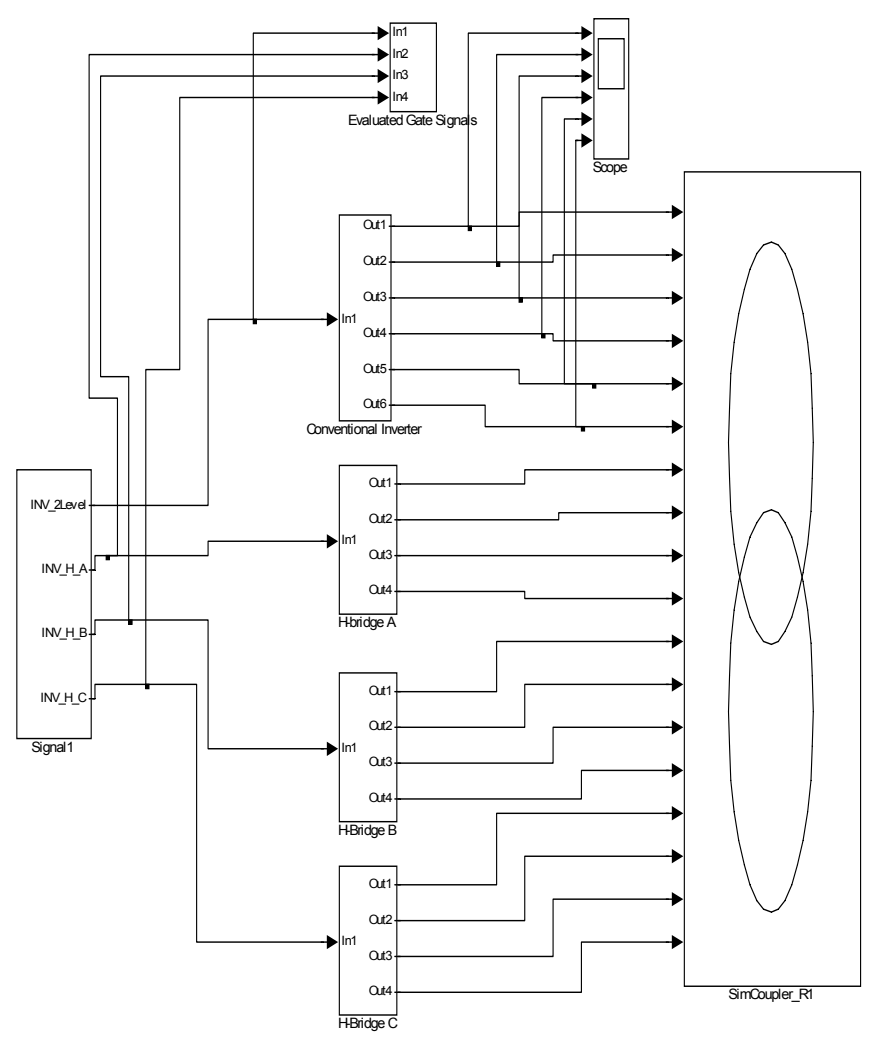

Fig. 5. SIMULINK control model for the hybrid multilevel inverter.

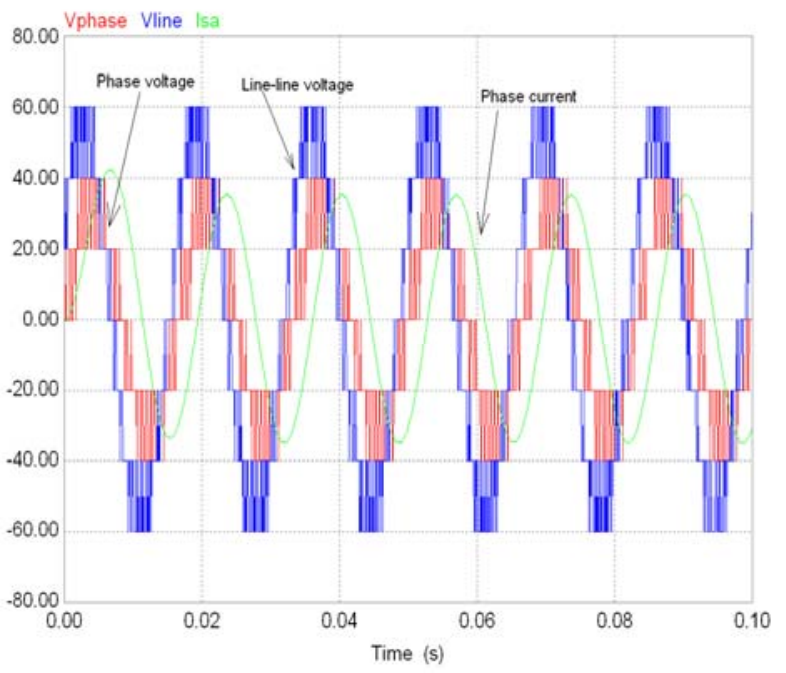

Fig. 6. Output line-line and phase voltage, phase current of the hybrid multilevel inverter $\left(\mathrm{m}_{\mathrm{a}}=0.8\right)$.

The PSIM model for the power circuit is shown in Fig. 4. PSIM provides a powerful simulation environment for power electronics applications. It is convenient and straightforward to build the power circuit model in PSIM because of its large module and device sources. Its control functions are completed in the MATLAB/SIMULINK. The mathematics models in the MATLAB/SIMULINK can realize the control functions. The control model is shown in Fig. 5. A SimCoupler module provides the interface between PSIM and MATLAB/SIMULINK for co-simulation. With the SimCoupler module, part of a system can be implemented and simulated in PSIM, and the rest of the system in MATLAB/SIMULINK. In PSIM, the SLINK_IN nodes receive values from SIMULINK, and the SLINK $\bar{O}$ OUT nodes send the values to SIMULINK. They are all control elements and can be used in the control circuit only. In SIMULINK, the SimCoupler model block is connected to the rest of the system through input/output ports.

One can therefore make full use of PSIM's capability in power simulation and MATLAB/SIMULINK's capability in control simulation in a complementary way. Fig. 6 shows the simulation results, which include phase voltage, line-line voltage, and phase current.

\section{EXPERIMENT VERIFICATION}

A $5 \mathrm{~kW}$ prototype using power MOSFETs as shown in Fig. 7 has been built in order to verify the proposed hybrid multilevel inverter. The load is a $15 \mathrm{hp}$ induction motor, which is loaded less than $5 \mathrm{~kW}$. Motor control function with the real-time variable output voltage and variable frequency is implemented by an Altera FLEX $10 \mathrm{~K}$ field programmable gate array (FPGA) controller. The capacitor voltage is detected by a voltage sensor and fed into the FPGA controller to realize the capacitor voltage regulation. 


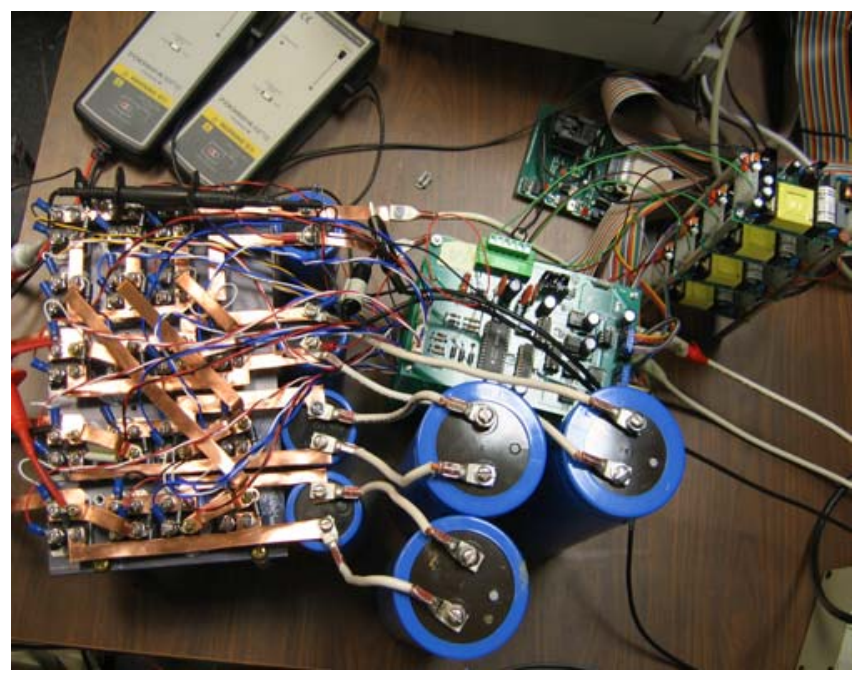

Fig. 7. A $5 \mathrm{~kW}$ hybrid multilevel inverter prototype.

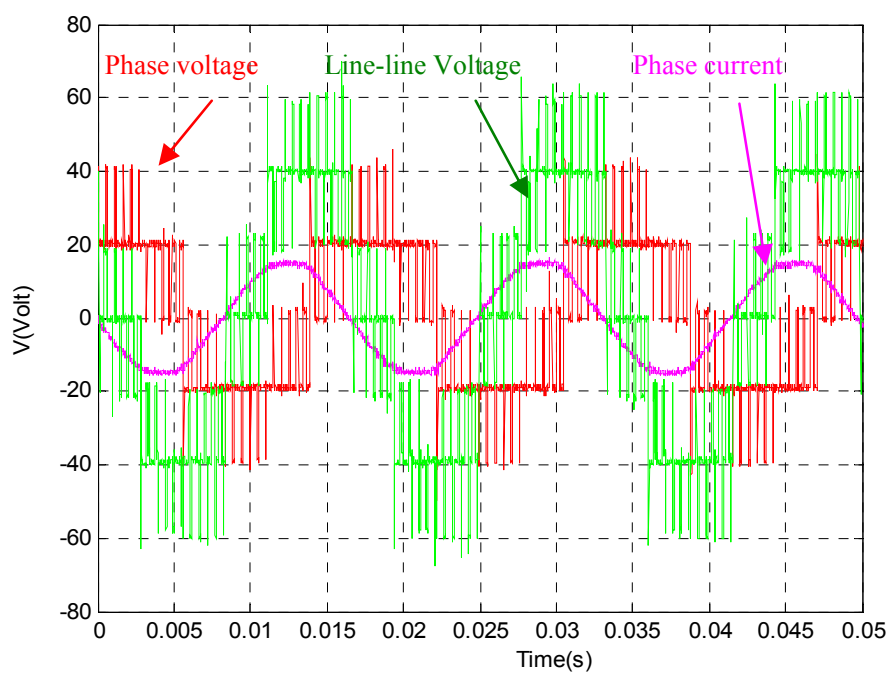

Fig. 8. Output line-line and phase voltage, phase current of the hybrid multilevel inverter $\left(\mathrm{m}_{\mathrm{a}}=0.8\right)$.

Fig. 8 shows the experiment results including phase voltage, line-line voltage, and phase current. The output phase voltage waveform is 5-level and the phase current waveform is close to sinusoidal. The experiment results verify the above simulation results.

\section{CONCLUSION}

A simulation model for the hybrid multilevel inverter is developed in the user-friendly PSIM and SIMULINK cosimulation platform. The inverter output is a 5-level phase voltage. The paper presents main circuit in PSIM, control models in the MATLAB/SIMULINK, co-simulation interface and simulation results in detail. The validity of the cosimulation platform is verified by the experiment results.

\section{REFERENCES}

[1] L. M. Tolbert, F. Z. Peng, T. G. Habetler, "Multilevel converters for large electric drives," IEEE Transactions on Industry Applications, vol.35, no. 1, Jan./Feb. 1999, pp. 36-44.

[2] J. S. Lai and F. Z. Peng, "Multilevel converters - A new breed of power converters," IEEE Transactions on Industry Applications, vol. 32, no.3, May. /June 1996, pp. 509-517.

[3] J. Rodríguez, J. Lai, and F. Peng, "Multilevel inverters: a survey of topologies, controls and applications," IEEE Transactions on Industry Applications, vol. 49, no. 4, Aug. 2002, pp. 724-738.

[4] S. Onoda, A. Emadi, "PSIM-based modeling of automotive power systems: conventional, electric, and hybrid electric vehicles" IEEE Transactions on Vehicular Technology, vol. 53, issue 2, 2004, pp. 390-395.

[5] D. Zhong B. Ozpineci, L. M. Tolbert, J. N. Chiasson, "Inductorless DCAC cascaded H-Bridge multilevel boost inverter for electric/hybrid electric vehicle applications," IEEE Industry Applications Conference, Sept. 2007, pp. 603-608.

[6] J. Liao, K. Corzine, M. Ferdowsi, "A new control method for single-DCsource cascaded H-Bridge multilevel converters using phase-shift modulation," IEEE Applied Power Electronics Conference and Exposition, Feb. 2008, pp.886-890.

[7] S. Khomfoi, L. M. Tolbert, "Multilevel power converters," Power Electronics Handbook, 2nd Edition Elsevier, 2007, ISBN 978-0-12-0884797, Chapter 17, pp. 451-482. 